\title{
Estratégia\&Negócios
}

ISSN 1984-3372

http://www.portaldeperiodicos.unisul.br/index.php/EeN/

\section{FATORES CRÍTICOS NA IMPLANTAÇÃO DO BALANCED SCORECARD-BSC}

\section{CRITICAL FACTORS IN IMPLEMENTING THE BALANCED SCORECARD-BSC}

\section{Fábio Augusto de Lucca Moreira}

Mestre em Administração e Controladoria pela Universidade Federal do Ceará - UFC.

E-mail: fabiomoreira02@uol.com.br

\section{Maria Naiula Monteiro Pessoa}

Professora do Programa de Pós-Graduação em Administração e Controladoria, da Universidade Federal do Ceará. Doutora em Engenharia da Produção pela Universidade Federal de Santa Catarina - UFSC.

E-mail:naiula@ufc.br

\section{Augusto Cezar de Aquino Cabral}

Professor do Programa de Pós-Graduação em Administração e Controladoria, da Universidade Federal do Ceará Doutor em Administração pela Universidade Federal de Minas Gerais - UFMG.

E-mail: cabral@ufc.br

\section{Sandra Maria dos Santos}

Professora do Programa de Pós-Graduação em Administração e Controladoria. Doutora e Pós-doutora em Economia pela Universidade Federal de Pernambuco - UFPE e da Universidade Federal do Ceará.

E-mail: smmsantos@ufc.br

\section{Vivianne Pereira Salas Roldan}

Professora da graduação semipresencial em Administração da Universidade Federal do Ceará. Mestre em Administração e Controladoria pela Universidade Federal do Ceará - UFC.

E-mail: vsalasroldan@gmail.com

Recebido em 01/01/2012. Aprovado em 14/12/2012. Disponibilizado em 04/03/2013. Avaliado pelo Sistema double blind review

R. eletr. estrat. neg., Florianópolis, v.5, n.3, p.57-89, set./dez. 2012 http://portaldeperiodicos.unisul.br/index.php/EeN/index
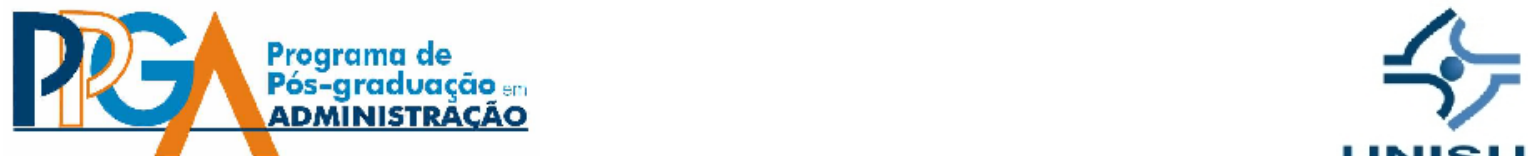

UNISUL

CCopyright 2008 UNISUL-PPGA/Estratégia e Negócios. Todos os direitos reservados. Permitida citação parcial, desde que identificada a fonte. Proibida a reprodução total. Em caso de dúvidas, consulte o editor: ademar.unisul@gmail.com; (48) 3229-1932. 


\section{RESUMO}

Inúmeras questões podem ser levantadas acerca dos fatores críticos para a implantação de modelos de gestão como o Balanced Scorecard (BSC). O êxito demanda a compreensão do modelo, por parte da equipe de implantação e dos colaboradores envolvidos. Ressalta-se que a indústria do entretenimento, em que se insere o Beach Park Hotéis e Turismo, possui particularidades que tornam ainda mais desafiadora a implantação do BSC, sendo um segmento que tenderá a crescer a uma taxa de 10,6\% ao ano até 2016. Tendo por foco esta organização e contexto, este estudo tem como objetivo identificar os fatores críticos da implantação do BSC, mediante um estudo de caso, descritivo. Os resultados evidenciaram os seguintes fatores críticos no insucesso na implantação do BSC: a ausência de uma cultura de planejamento estratégico; a complexidade do negócio e do projeto; o histórico de um estilo de gestão centralizador e autoritário; a centralização do BSC no topo; restrição de tempo dos gestores para se dedicar ao projeto; a falta de um sistema de informação, para dar suporte ao projeto; a não realização de treinamentos e o despreparo da consultoria externa. Na promoção da mudança organizacional, faltaram o envolvimento adequado das lideranças e o apoio da gestão da cúpula. Em casos de sucesso, o histórico de uma gestão voltada para o aprendizado, serve como base para a definição adequada das necessidades críticas da organização, e na definição dos indicadores adequados, fatores que, no caso em foco, mostraram-se ausentes em uma empresa sem cultura de planejamento.

Palavras-chave: Fatores Críticos. Balanced Scorecard. Indústria de Entretenimento.

\section{INTRODUÇÃO}

Na década de 1990, o Balanced Scorecard (BSC) foi proposto por Robert Kaplan e David Norton, como uma ferramenta única, para se entender a organização, em uma perspectiva estratégica, por meio de indicadores balanceados, interligados 
pelas relações de causa e efeito de seus objetivos, norteando os gestores na definição do que é relevante e do que é secundário.

O Balanced Scorecard foi criado no intuito de fazer com que a empresa considerasse em sua estratégia as necessidades de seus clientes e de seus processos, sem perder o foco nos controles financeiros, até então utilizados como vetores únicos de resultados. Com sua utilização, consegue-se desenhar a estratégia da empresa, medindo cada ação e possibilitando que se entenda exatamente onde se quer chegar e qual o caminho que se deve seguir.

Toda esta argumentação a favor do BSC parece indicar que a simples implantação do BSC promove um diferencial na empresa que, doravante, tenderá a entrar em um processo de crescimento contínuo. Porém, parte das empresas que optam pela implantação do BSC fracassa, não chegando a finalizar essa implantação e decidindo buscar um novo modelo de gestão.

Analisando-se a literatura empírica sobre o Balanced Scorecard, constatase que a maior parte dela discute sobre a adoção do BSC em segmentos tradicionais do setor privado, sendo bastante restritos os estudos no setor público, nas organizações não governamentais sem fins lucrativos e no campo da economia criativa, como a indústria de entretenimento (NORTHCOTT; TAULAPAPA, 2012; YOUNG et al., 2006).

No campo do entretenimento, em especial, a não existência de um modelo específico de BSC é considerada uma das barreiras à sua utilização (MARCHESAN NETO, 2002). Também, dentre os estudos sobre o BSC na indústria de entretenimento, poucos são os que discutem sua implantação real. A presente pesquisa busca contribuir na redução desta lacuna, identificando os fatores críticos para a implantação do BSC no Beach Park Hotéis e Turismo, localizado em Fortaleza-CE.

Ressalta-se que a indústria do entretenimento, em que se insere a empresa foco deste estudo, possui particularidades que tornam ainda mais desafiadora a implantação de um modelo de gestão, pois fatores como a sazonalidade, a influência climática e até mesmo a velocidade de inovações tendem a exercer fortes pressões na operação do negócio, podendo por em xeque a sobrevivência da organização. De 
acordo com a PropMark (2012), a indústria de entretenimento e mídia crescerão a uma taxa de 10,6\% ao ano até 2016, tendo movimentado no Brasil, no ano de 2011 , 39,1 bilhões de dólares.

Em destinos turísticos como Fortaleza, devem-se considerar outros itens que influenciam o resultado da organização, tais como o valor do dólar, a acessibilidade ao transporte aéreo, o investimento do governo estadual em mídia e o interesse dos grandes operadores de turismo no destino em questão. Considerando-se a singularidade do setor e a relevância de se compreender os impactos positivos e negativos de um novo modelo de gestão, buscou-se nesta pesquisa responder o seguinte problema: Quais foram os fatores críticos que impediram a implantação do BSC no Beach Park?

Como objetivo geral, o estudo pretende identificar os fatores críticos para a implantação do BSC, mediante a análise de uma empresa da indústria do entretenimento que não conseguiu concluir o processo de implantação. Para isso, foram definidos os seguintes objetivos específicos: 1) analisar os fatores impeditivos na formulação da estratégia da empresa; 2) identificar os fatores impeditivos na implantação do mapa estratégico, dividido em perspectivas; 3) avaliar os fatores impeditivos na utilização da leitura de resultados por meio de indicadores balanceados; 4) analisar os fatores impeditivos da conclusão da implementação do BSC. Busca-se, assim, entender o motivo de um modelo de gestão, genericamente bem aceito na literatura e em casos empíricos, não funcionar ou não conseguir completar sua implantação em algumas empresas.

No que se refere aos aspectos metodológicos, o estudo é descritivo quanto aos fins, e faz uso de métodos quantitativos e qualitativos de pesquisa. Quanto aos meios, é uma pesquisa bibliográfica e de campo, tendo sido realizada mediante um estudo de caso. Em termos de estrutura, este artigo tem, além desta seção de introdução, uma segunda seção que apresenta o referencial teórico sobre o Balanced Scorecard, discutindo os fatores críticos para sua implementação apontados pela literatura; uma terceira seção, que apresenta os estudos sobre o Balanced Scorecard 
na indústria de entretenimento; a quarta e quinta seção, que se referem à metodologia adotada no estudo e a apresentação dos resultados; e a sexta seção, que apresenta as considerações finais do estudo.

\section{BALANCED SCORECARD (BSC) COMO FERRAMENTA DE GESTÃO ESTRATÉGICA}

O Balanced Scorecard traduz a missão e a estratégia da empresa em metas e métodos, acompanhando-os por meio de indicadores balanceados e das relações de causa e efeito na consecução de seus objetivos. Confrontando a tendência geral das empresas em mensurar seus resultados sempre mediante indicadores financeiros, o BSC inova ao inserir, no mesmo nível de importância, tanto a parte financeira como a dos ativos intangíveis necessários para o crescimento futuro (KAPLAN; NORTON, 1997).

O termo Scorecard foi utilizado para ressaltar a forma como os resultados dos períodos passaram a ser demonstrados, similar a um placar (Scorecard); o termo Balanced, por sua vez, foi inserido para enfatizar o equilíbrio existente entre objetivos de curto e longo prazo, medidas financeiras e não financeiras, entre indicadores de ocorrência/tendência, e entre as perspectivas financeira, clientes, processos internos e aprendizado e crescimento, sintetizados na Figura 1, tratando de aspectos internos e externos à organização (KAPLAN; NORTON, 1992).

Figura 1 - Perspectivas do Balanced Scorecard

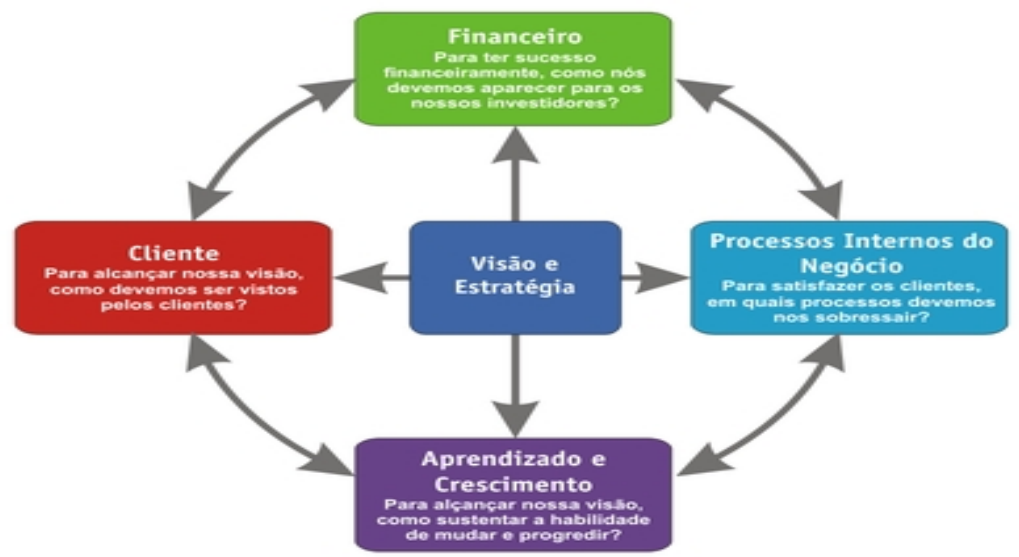

Fonte: Adaptado de Kaplan e Norton (1997).

R. eletr. estrat. neg., Florianópolis, v.5, n.3, p.57-89, set./dez. 2012 
Por sua capacidade de fazer a articulação entre a estratégia e a ação, o Balanced Scorecard se enquadra mais como um sistema de gestão estratégica do que de medidas táticas. Por meio de suas quatro perspectivas, o BSC integra os componentes da estratégia, sem negligenciar a visão financeira de passado, permite que se planeje o futuro mediante uma abordagem sistêmica, apoiada por relações de causa e efeito entre suas metas e objetivos (KAPLAN; NORTON, 1997).

A seguir, discute-se o referencial teórico acerca dos fatores de risco para a implantação do Balanced Scorecard, conforme a literatura nacional e internacional.

\subsection{FATORES CRÍTICOS NA IMPLEMENTAÇÃO DO BALANCED SCORECARD}

O crescimento do uso do BSC tem sido notável, sendo utilizado por $60 \%$ das empresas do Fortune 500 (BEBER; RIBEIRO; KLIEMANN NETO, 2011). No entanto, segundo Moreira e Caleffe (2006), 70\% das experiências com o BSC fracassam. Embora os fundamentos do BSC representem um avanço na proposta de comunicação, alinhamento e implementação da estratégia, bem como na orientação para a formulação de modelos de medição de desempenho na lógica sistêmica, ainda é possível identificar alguns pontos de fragilidade na concepção de sua estrutura original, como evidenciam Attadia, Canevarolo e Martins (2003).

Nesta seção, apresenta-se o levantamento na literatura acerca dos fatores de risco na implantação do BSC, sumarizado no Quadro 1. Os fatores de sucesso ou fracasso destacados nos estudos são aqui compreendidos como fatores de risco ou fatores críticos para a implantação do BSC. Eles foram subdivididos em grupos conforme sua ocorrência. Tais riscos podem estar associados ao envolvimento da equipe, à estrutura da organização, à implantação, ao processo ou objetivos e às influências externas.

Analisando 71 estudos de casos apresentados em anais de congressos (2000 a 2008) e publicados em revistas indexadas no sistema Qualis Capes, Rocha e Lavarda (2011) identificam os fatores críticos de sucesso para implantação do BSC em 
64,8\% desses estudos: $17,4 \%$ apontam a cultura organizacional como fator crítico de sucesso, $13,04 \%$ destacam o comprometimento gerencial, 10,9\% o comprometimento dos funcionários, e 8,7\% a evolução no sistema de informação. Ressalta-se que 59,2\% desses casos foram realizados em empresas privadas.

Realizando um levantamento na literatura sobre as principais dificuldades para implantação do BSC nas organizações, nas Bases dos Periódicos da Capes, Proquest, Scopus, ISI Web of Knowledge, Scielo, entre outros, entre dezembro de 2009 a abril de 2010, Croce Filho e Costa (2010) identificaram várias falhas na implantação ou execução do Balanced Scorecard, dentre elas: falta de comprometimento da alta administração; ser uma ação isolada da alta administração; não dividir papéis e responsabilidades; BSC como evento único e não como processo contínuo; perspectivas não balanceadas; não conseguir traduzir a estratégia; falta de alinhamento com os sistemas e objetivos existentes; e comunicação e treinamento não efetivo nas diversas fases.

Realizando o mesmo levantamento bibliográfico no Portal Periódicos Capes (2002 a 2012), com uso das palavras-chaves "Balanced Scorecard+success", "Balanced Scorecard+unsuccessul", "Balanced Scorecard+failure", "Balanced Scorecard+barriers", e "Balanced Scorecard+implementation", também foram encontrados artigos internacionais empíricos que discutem os fatores críticos para o sucesso da implementação do BSC: Kasurinen (2002), Chan (2004), Wagner e Kaufmann (2004), Yeung e Connell (2006), e Northcott e Taulapapa (2012).

Por meio de uma pesquisa-ação, Kasurinen (2002) analisa os fatores que influenciam a mudança na gestão contábil, focando a introdução do Balanced Scorecard. No estudo de caso realizado, Kasurinen (2002) identificou como barreiras à implementação do BSC: dificuldade para especificar a estratégia da unidade de negócios, confusão sobre os reais objetivos do projeto BSC, sucesso financeiro da unidade de negócios pareceu limitar a motivação para o projeto, na definição das estratégias específicas; ambiente de projeto complexo, com falhas na coordenação e organização; falta de uma estrutura de medição integrada; renúncia do gerente geral 
da unidade de negócios, reduzindo a motivação para a aplicação do BSC; falta de tempo para se dedicar na definição dos indicadores; e mudança da organização para outro local, com consequente combinação de estruturas, alterando as informações de ordem financeira.

Aplicando uma pesquisa junto aos governos municipais dos Estados Unidos e Canadá, Chan (2004) constatou que o uso do BSC entre eles ainda é limitado. Os gestores pesquisados da amostra do Canadá destacaram como motivações para a não implementação do BSC, a falta de um sistema de informação adequado para dar suporte ao BSC, financiamento inadequado, e falta de comprometimento da alta administração, pelo tempo restrito dos gestores, muito ocupados com problemas de curto prazo. Os administradores de instituições públicas que implementaram o BSC destacaram a falta de articulação do Balanced Scorecard com as recompensas aos empregados e a resistência organizacional à mudança como fatores que prejudicaram a implementação do BSC em suas organizações.

Quadro 1 - Possibilidades de riscos na implantação do BSC

\begin{tabular}{|c|c|c|}
\hline Dimensões Centrais & Fatores de Risco & Autores \\
\hline \multirow{6}{*}{$\begin{array}{l}\text { Envolvimento da } \\
\text { equipe }\end{array}$} & Falta de comprometimento da alta administração & \multirow{6}{*}{$\begin{array}{l}\text { Chan (2004), Wagner e } \\
\text { Kaufmann (2004), Prieto et } \\
\text { al. (2005), Beber et al. } \\
\text { (2006), Croce Filho e Costa } \\
\text { (2010), Rocha e Lavarda } \\
\text { (2011), Northcott e } \\
\text { Taulapapa (2012) }\end{array}$} \\
\hline & Gestão muito ocupada - problemas de curto prazo & \\
\hline & Envolvimento de poucas pessoas & \\
\hline & Encastelamento do BSC no topo & \\
\hline & Não dividir papéis e responsabilidades & \\
\hline & Resistência organizacional à mudança & \\
\hline & & \\
\hline \multirow{4}{*}{$\begin{array}{l}\text { Estrutura da } \\
\text { organização }\end{array}$} & \begin{tabular}{|l} 
Organização não está voltada para o aprendizado \\
Empresa não possui estratégia definida
\end{tabular} & \multirow{4}{*}{$\begin{array}{c}\text { Kasurinen (2002), Wagner } \\
\text { e Kaufmann (2004), Prieto } \\
\text { et al. (2005), Yeung e } \\
\text { Connell (2006), Beber et } \\
\text { al. (2006), Croce Filho e } \\
\text { Costa (2010), Northcott e } \\
\text { Taulapapa (2012) }\end{array}$} \\
\hline & Confundir-se com a estratégia & \\
\hline & $\begin{array}{l}\text { Dificuldades no acesso e entendimento das } \\
\text { informações }\end{array}$ & \\
\hline & Complexidade do ambiente & \\
\hline \multirow{7}{*}{ Implantação } & Falta de discussão da estratégia & \multirow{7}{*}{$\begin{array}{l}\text { Kasurinen (2002), Wagner } \\
\text { e Kaufmann (2004), Prieto } \\
\text { et al. (2005), Beber et al. } \\
\text { (2006), Croce Filho e Costa } \\
\text { (2010), Northcott e } \\
\text { Taulapapa (2012) }\end{array}$} \\
\hline & Estar baseado na estratégia & \\
\hline & \begin{tabular}{|l|} 
Medidas mal projetadas \\
\end{tabular} & \\
\hline & \begin{tabular}{|l|} 
Utilização no nível organizacional errado \\
\end{tabular} & \\
\hline & Desenvolvimento muito demorado & \\
\hline & Amplitude inadequada do projeto & \\
\hline & Relações de causa e efeito mal estabelecidas & \\
\hline
\end{tabular}


Quadro 1 - Possibilidades de riscos na implantação do BSC

\begin{tabular}{|c|c|c|}
\hline Dimensões Centrais & Fatores de Risco & Autores \\
\hline \multirow{9}{*}{ Processos e Objetivos } & $\begin{array}{l}\text { Problemas na circulação das informações; falta de } \\
\text { suporte de um sistema de informação }\end{array}$ & \multirow{9}{*}{$\begin{array}{c}\text { Andrade e Hoffman } \\
\text { (2004), Chan (2004), } \\
\text { Wagner e Kaufmann } \\
\text { (2004), Prieto et al. (2005) } \\
\text { Yeung e Connell (2006), } \\
\text { Beber et al. (2006), Croce } \\
\text { Filho e Costa (2010) } \\
\text { Northcott e Taulapapa } \\
\text { (2012) }\end{array}$} \\
\hline & BSC como projeto de uma única área & \\
\hline & Falta de treinamento & \\
\hline & $\begin{array}{l}\text { BSC para fins de remuneração; falta de articulação } \\
\text { do balanced scorecard com as recompensas aos } \\
\text { empregados }\end{array}$ & \\
\hline & Choque com outras ferramentas administrativas & \\
\hline & Falta de alinhamento com sistemas existentes & \\
\hline & Diferenças na definição das medidas & \\
\hline & $\begin{array}{l}\text { Dificuldade em monitorar as medidas não } \\
\text { financeiras }\end{array}$ & \\
\hline & $\begin{array}{l}\text { Estabelecimento de objetivos de curto e longo } \\
\text { prazo }\end{array}$ & \\
\hline \multirow{3}{*}{ Influências Externas } & Fusões e Aquisições; & \multirow{3}{*}{$\begin{array}{c}\text { Beber et al. (2006), } \\
\text { Wagner e Kaufmann } \\
\text { (2004), Prieto et al. (2005) }\end{array}$} \\
\hline & Interferência sindical & \\
\hline & Contratação de consultores inexperientes & \\
\hline
\end{tabular}

Fonte: Elaborado pelos autores, 2012.

Wagner e Kaufmann (2004) analisaram a aplicação do BSC para a unidade de compras e os obstáculos mais comuns enfrentados pelos gestores no processo de implantação. Dentre esses obstáculos, os autores destacam a ausência de comprometimento, que pode ser consequência da subestimação dos gestores quanto aos esforços necessários para a implantação do BSC, ou falha de comunicação sobre os reais objetivos do BSC que pode levar os empregados a entender o BSC como mais uma moda que será descartada, ou ainda, um histórico negativo da empresa nas experiências de implementação de novos processos de gestão, criando uma resistência geral. Destacam ainda como obstáculos, a falta de experiência dos consultores externos, a ausência de suporte da alta gestão, problemas de integração dos sistemas, falta de visão e estratégia de compra e dificuldades na definição dos objetivos estratégicos e relações de causa e efeitos.

Yeung e Connell (2006) estudaram a aplicação do BSC em uma organização não lucrativa em Hong Kong, e identificaram que os fatores que mais contribuíram para a implementação bem sucedida foram: formação e aprendizagem contínua em todos os níveis, realização de reuniões e discussões, sessões de comunicação e de 
envolvimento do pessoal em todos os níveis, articulação clara e compartilhada da missão e estratégia da organização, apoio e comprometimento da alta administração ao longo do processo.

O uso do BSC nas organizações públicas para melhoria da performance da gestão foi analisado por Northcott e Taulapapa (2012). Os autores destacam como fatores de sucesso para a implementação do BSC, o comprometimento da alta administração, ênfase na excelência do desempenho, realização de treinamentos, estratégias e metas organizacionais claras e aplicação adequada de programas de incentivo e financiamento. Esses fatores não são específicos do setor público, pois ocorrem igualmente no setor privado.

Na próxima seção, são destacados os estudos empíricos sobre o Balanced Scorecard na indústria de entretenimento.

\subsection{BALANCED SCORECARD NA INDÚSTRIA DE ENTRETENIMENTO}

Um recente estudo da Pricewaterhouse Coopers, em 2008, aponta que a indústria de mídia e entretenimento global injetará sozinha \$2,2 trilhões na economia mundial em 2012 (UNCTAD, 2011). De acordo com Trigo (2003), o conceito de entretenimento surgiu entre o século XIX e XX, com a estruturação do capitalismo em sua fase pós-industrial. Para Trigo (2003), o entretenimento pode ser compreendido como um espetáculo para massas, diferenciando-se da arte, que trata seu espectador, ouvinte ou leitor como indivíduo. O entretenimento é a satisfação que tem raiz na alma da população, fazendo parte do universo do lazer que abrange a recreação, o turismo, as atividades esportivas informais, entre outros segmentos (TRIGO, 2003).

A indústria do entretenimento é campo imerso na economia criativa, definida pela UNCTAD (2011) como um conjunto de atividades que abrange aspectos econômicos, culturais, e sociais que interagem com os objetivos do turismo, da propriedade intelectual e tecnológica. De acordo com Jeacle (2009), a indústria de entretenimento tem sido amplamente ignorada pela academia, em particular, na área 
de contábeis, o que é lamentável dado a grande escala da indústria e de seu impacto. Young et al. (2006) afirmam que estudos sobre os impactos da contabilidade gerencial e seus sistemas de controle têm sido realizados em vários contextos, como no da fabricação, hospitais e setor público, sendo poucas pesquisas realizadas no âmbito das indústrias criativas, em que estão inseridos os campos de entretenimento musical, de televisão, cinema, jogos, entre outros. Ambos, Young et al. (2006) e Jeacle (2009) estudaram a contabilidade na indústria criativa do cinema.

A economia criativa é um campo, portanto, carente ainda de mais estudos quanto às características de sua gestão e dos processos que são necessários para aperfeiçoá-la para o alcance do melhor desempenho. Como explicam Lampel et al. (2009), satisfazer o consumidor na economia criativa é um grande desafio, pois os bens culturais obtêm seu valor por meio das experiências subjetivas, com o uso intensivo de símbolos para influenciar a percepção e a emoção. A imprevisibilidade dessa experiência subjetiva torna complicada a definição clara de padrões de qualidade dos produtos e serviços ofertados. Discutir como aplicar modelos de gestão estratégica como o BSC no âmbito da economia criativa é contribuir, dessa forma, para o encontro das práticas gerenciais mais adequadas para o melhor gerenciamento dos recursos criativos, essenciais para a sobrevivência em longo prazo das organizações desse setor.

Assim como no meio acadêmico internacional, no Brasil as pesquisas de contabilidade gerencial no setor da economia criativa, como em torno da indústria de entretenimento, são ainda restritas. Com relação à metodologia do Balanced Scorecard (BSC) e sua aplicação na indústria de entretenimento, foram encontrados no meio acadêmico nacional os estudos de Marchesan Neto (2002), Celestino (2003), Cruz Júnior et al. (2005), Rosa e Lunkes (2006), e Bechara (2008). No meio acadêmico internacional, os estudos incluem as pesquisas de Foreman (2006) e Santos (2011).

Marchesan Neto (2002) analisou a implantação de um Sistema de Avaliação de Desempenho baseado na metodologia do Balanced Scorecard (BSC), em uma empresa de serviços que atua no setor de entretenimento, destacando suas 
dificuldades e benefícios, e demonstrando que a aplicação do BSC em empresas de serviços de entretenimento é possível.

As principais dificuldades para implantação do BSC identificadas pelo estudo de Marchesan Neto (2002) foram: 1) a dificuldade de convencer os integrantes do projeto quanto à importância de se adotar uma visão e missão factível e de fácil entendimento para todos; foi necessário que a liderança empreendesse um maior esforço para conscientizar a equipe quanto à relevância do assunto para o desenvolvimento do projeto; 2) resistência dos integrantes do projeto quanto a se utilizar o BSC para coordenar o processo de implementação das estratégias, devido à própria ausência de uma cultura de planejamento estratégico; a resistência foi vencida quando se diagnosticou que as ações e projetos em andamento na empresa, em sua maioria, não estavam alinhados com as estratégias propostas pela alta direção; 3) conhecimento superficial dos integrantes do projeto, acerca do BSC, com exceção do diretor superintendente da empresa; 4) ausência de cases disponíveis de implementação do BSC no setor de atuação da empresa, obrigando a organização a realizar coleta, análise de informação e desenvolvimento de indicadores sem um modelo definido em mãos; 5) dificuldades relacionadas à disponibilidade e sensibilidade da equipe; 6) demora para a continuidade do processo de tomada de decisão, em seguida ao início da utilização dos indicadores.

Os benefícios trazidos pela implementação do Balanced Scorecard, identificados por Marchesan Neto (2002) foram: 1) o alinhamento das iniciativas e projetos das diversas áreas da empresa, com o seu planejamento estratégico; 2) o mapeamento estratégico tornou o processo de tomada de decisão mais ágil e acertado; 3) percepção de uma gestão mais equilibrada, balanceada pelas 4 perspectivas do BSC.

Santos (2011) aborda a implantação do Balanced Scorecard no campo específico da Cultura e da gestão pública, sendo o objetivo de seu estudo a elaboração de um sistema de BSC para o Teatro Nacional D. Maria II, em Portugal. 
No contexto dos clubes esportivos, organizações que lidam com processos de lazer e entretenimento, Cruz Júnior et al. (2005) investigam como se deu o alinhamento entre estratégia e estrutura. Considerando a abordagem do Balanced Scorecard, constatam que os indicadores utilizados nos diferentes processos da organização têm dado prioridade maior apenas às perspectivas clientes e processos internos.

Foreman (2006) realizou um estudo na Liga Australiana de Futebol, onde procurou identificar as práticas de governança dos clubes da Liga, determinar o desempenho dos clubes, examinar as ligações entre governança e desempenho e identificar características comuns de governança nos clubes. Analisando o desempenho dos Clubes à luz do BSC, Foreman (2006) constata que, dentre os passos de implementação do BSC, os clubes só executaram os seguintes: determinação dos objetivos, determinação da medida de desempenho para cada meta e registro do desempenho atual. Os clubes não realizam o passo da determinação do nível de desempenho que se deseja como meta para cada medida.

No campo dos megaeventos esportivos, Bechara (2008) discute o planejamento e a gestão dos megaeventos, e propõe em um dos tópicos de sua pesquisa, um modelo sintetizado de gestão estratégica à luz das quatro perspectivas do BSC. O autor afirma que o BSC auxiliará a organização do Megaevento a ser eficaz no alcance dos objetivos determinados em seus planos estratégicos, priorizando mais adequadamente suas ações.

Considerando os hotéis como um local de entretenimento do turista (LUNKES, 2004), assim como os restaurantes, foram encontradas pesquisas em torno da implementação do BSC nessas atividades, destacando-se as de Celestino (2003) e Rosa e Lunkes (2006).

Pesquisando a rede hoteleira, Rosa e Lunkes (2006) constataram que apenas 2\% das 150 empresas hoteleiras localizadas em Florianópolis utilizam o BSC, consistindo em hotéis de grande porte. Os autores também utilizaram as 4 perspectivas do BSC para elaborar um perfil de gestão desses hotéis, identificando 
que: na perspectiva financeira os hotéis se fundamentam pelo faturamento; na perspectiva dos clientes estão mais voltados para satisfação e nível de ocupação dos hóspedes; na perspectiva dos processos internos, os hotéis se preocupam mais com a qualidade (satisfação do cliente e infraestrutura), produtividade (percentual de hóspedes atendidos) e tempo (desempenho quanto à permanência dos hóspedes); e na perspectiva de aprendizado e crescimento, os hotéis se preocupam, principalmente, com a capacitação e produtividade dos colaboradores, assim como com a motivação e retenção deles. Constatações semelhantes foram encontradas por Celestino (2003), em sua pesquisa em hotéis de médio e grande porte no Rio Grande do Norte, em que apenas $16,2 \%$ dos 37 hotéis pesquisados utilizam o BSC.

Pelo exposto, observa-se que não só as pesquisas, mas a própria implementação do Balanced Scorecard no contexto da indústria de entretenimento tem sido restrita, sendo a falta de um modelo disponível, um dos obstáculos à sua utilização, como dito por Marchesan Neto (2002). A maioria dos estudos faz uso da lógica teórica do Balanced Scorecard para compreender a gestão estratégica do desempenho nas empresas analisadas, e uma minoria aborda a implantação real dessa ferramenta gerencial. Nas seções seguintes é apresentada a metodologia aplicada na condução do estudo para o alcance dos seus objetivos, os resultados encontrados, a discussão dos dados empíricos com o referencial teórico e as considerações finais.

\section{METODOLOGIA}

A pesquisa quanto aos fins é de natureza descritiva, e quanto aos procedimentos o estudo é bibliográfico e de campo, tendo sido realizado mediante um estudo de caso em uma empresa da indústria do entretenimento. O estudo de caso possibilita que o fenômeno seja investigado dentro do seu contexto real, e sua aplicação é ideal quando os limites entre eles não estão claros (YIN, 2005). Faz uso de métodos quantitativos e qualitativos. 
A empresa Beach Park Hotéis e Turismo S/A foi escolhida por ser uma organização cujo ramo principal é o entretenimento, e que engloba uma diversidade de atividades que torna desafiador a implementação do BSC. Também foi decisivo na escolha desta empresa o fato de ela ser a maior da América Latina no ramo de entretenimento e uma das maiores do Brasil no ramo da hotelaria.

A empresa foi fundada em 1985 como um restaurante de praia, e em pouco tempo passou a ser um dos locais mais procurados da capital cearense. Em 1989, inaugurou seu primeiro brinquedo que, mais tarde, iria torná-lo o maior parque aquático da América latina. Atualmente, o complexo Beach Park se divide em unidades de negócios diversificadas, atuando em segmentos diferentes dentro da indústria do entretenimento e da hospitalidade. As unidades de negócios atuais são: a) Parque aquático; b) Restaurante de praia; c) Rede hoteleira; d) Administradora de condomínios; e) Lojas de conveniências, confecções e presentes; f) Timeshare; e g) Centro de convenções e eventos (BEACH PARK HOTÉIS E TURISMO S/A, 2012).

A coleta de dados foi baseada em dados primários, obtidos mediante a aplicação de questionário e entrevista semiestruturada. O questionário foi formado por 32 questões fechadas, divididas em seis grupos, sendo o primeiro referente aos dados dos pesquisados e os demais relativos aos fatores de risco da implantação do BSC destacados no referencial teórico: 1) envolvimento da equipe; 2) estrutura da organização; 3) implantação do BSC; 4) falha no processo ou nas definições dos objetivos; e 5) fatores externos.

O questionário tinha a finalidade de identificar os fatores de risco na implantação do Balanced Scorecard. A entrevista semiestruturada teve o objetivo de dar suporte e esclarecer alguns pontos do questionário aplicado, ao mesmo tempo em que visava fornecer subsídios para a compreensão da situação da empresa, de sua administração e forma de organização, no período da implantação do BSC.

Os sujeitos da pesquisa são gestores da empresa Beach Park Hotéis e Turismo S/A que participaram da implantação do Balanced Scorecard na empresa. 
Participaram da pesquisa, sessenta e um gestores, entre diretores, gerentes, supervisores, coordenadores, e outros.

Os procedimentos para análise dos dados compreenderam dois momentos. No que diz respeito aos dados obtidos no questionário, estes foram tabulados por meio do aplicativo Microsoft Office Excel 2007, sendo feito uso da estatística descritiva, com a análise percentual da frequência de respostas. Com relação às informações obtidas nas entrevistas, fez-se uso da análise de conteúdo temática, sendo definidos os seguintes temas: a) situação da empresa; b) situação da administração; c) forma de organização; d) processo de implantação do BSC. A análise de conteúdo temática permite que sejam feitas relações entre o referencial teórico que norteia o estudo e as informações empíricas coletadas na pesquisa de campo (BARDIN, 2003).

\section{FATORES CRÍTICOS NA IMPLANTAÇÃO DO BSC NO BEACH PARK HOTÉIS E TURISMO} S/A

Tomando-se por base os dados da pesquisa de campo, apresenta-se, inicialmente, uma síntese do contexto em que se encontrava o Beach Park Hotéis e Turismo à época da decisão de implementação de um novo modelo de gestão, o Balanced Scorecard. A implantação do BSC iniciou em meados de 2005 e foi cancelada ao final de 2007.

Originalmente, a empresa possuía três sócios proprietários e sua administração era feita por um desses sócios, cujo estilo de gestão era centralizador e autoritário, gerando dificuldades em sua operação. Por exemplo, o turnover era elevadíssimo e o grau de satisfação e motivação da equipe era extremamente baixo. Essa centralização fazia com que bons profissionais não resistissem muito tempo na empresa, que, pouco a pouco foi sendo ocupada por pessoas de confiança desse gestor, independentemente do mérito. Em julho de 2003, esse sócio deixou a sociedade, cabendo aos dois sócios, até então omissos, assumir a gestão. No final de 
2003, foi contratado um gestor para assumir o negócio. Os colaboradores não especializados foram substituídos. Em junho de 2004, a empresa deixou de ter um perfil de empresa familiar, tornando-se profissionalizada. Durante o segundo semestre de 2004 e o primeiro semestre de 2005, buscou-se decidir qual a melhor estratégia ou programa de gestão a ser adotado para o redirecionamento da empresa, tendo o Balanced Scorecard sido escolhido como a ferramenta de gestão a ser adotada.

\subsection{ANÁLISE DOS FATORES IMPEDITIVOS NA IMPLANTAÇÃO DO BSC}

Para avaliar a implantação do BSC no Beach Park Hotéis e Turismo S/A e identificar os motivos pelos quais os resultados esperados não foram alcançados, foi realizada uma pesquisa com 61 gestores que faziam parte do quadro de funcionários no período de implantação.

Conforme os dados obtidos, a implantação ficou quase que exclusivamente restrita aos diretores e gerentes, subgrupo em que se verificou $100 \%$ de participação, em oposição a apenas $25 \%$ dos supervisores e nenhum dos coordenadores e de outras funções. O conhecimento da estratégia é vital na implementação do BSC, pois não se pode fazer com que uma equipe chegue a um resultado se essa equipe não entende qual o caminho a percorrer. Apesar disso, a pesquisa evidenciou que, na empresa pesquisada, a estratégia não foi discutida por todos (Tabela 1). Dos pesquisados, $61 \%$ sequer ouviram falar em estratégia e $23 \%$ receberam somente um comunicado sobre ela.

Tabela 1 - Discussão da estratégia antes da implantação

A estratégia foi discutida por todos antes da implantação?

\begin{tabular}{|l|c|c|c|}
\hline & \multicolumn{4}{c}{ A estratégia foi discutida por todos antes da implantação? } \\
\hline & Sim, foi discutida antes & Não, apenas foi comunicada & $\begin{array}{l}\text { Nunca ouvi falar deste } \\
\text { assunto }\end{array}$ \\
\hline Diretores e Gerentes & $86 \%$ & $14 \%$ & $0 \%$ \\
\hline Supervisores & $38 \%$ & $38 \%$ & $25 \%$ \\
\hline Coordenadores & $0 \%$ & $67 \%$ & $33 \%$ \\
\hline Outros & $3 \%$ & $15 \%$ & $82 \%$ \\
\hline Totalizador & $16 \%$ & $23 \%$ & $61 \%$ \\
\hline
\end{tabular}

Fonte: Elaborado pelos autores a partir de dados da pesquisa, 2009. 
Nas reuniões sobre o BSC, apenas $21 \%$ da equipe participou, estando os diretores e gerentes presentes em sua maioria, e em menor número, os supervisores. Da equipe de base, $61 \%$ nem sequer tomaram conhecimento da existência dessas reuniões. A Tabela 2 mostra outro problema. Ao ser perguntado se o BSC era aplicado visando o benefício de todos os setores, $65 \%$ dos pesquisados afirmaram não ter tomado conhecimento dessa implantação e, para $20 \%$, o BSC era voltado com mais intensidade para alguns setores.

Tabela 2 - Foco do BSC em relação aos setores da empresa Na sua opinião, o BSC era voltado com mais intensidade para algum setor específico?

\begin{tabular}{|c|c|c|c|c|c|}
\hline & $\begin{array}{c}\text { Sim, para } \\
\text { TI }\end{array}$ & $\begin{array}{c}\text { Sim, para } \\
\mathrm{RH}\end{array}$ & $\begin{array}{c}\text { Sim, para } \\
\text { alguns setores }\end{array}$ & $\begin{array}{c}\text { Não, estava voltado } \\
\text { para todos os } \\
\text { setores }\end{array}$ & $\begin{array}{c}\text { Nunca ouvi falar } \\
\text { desse assunto }\end{array}$ \\
\hline Diretores e Gerentes & $0 \%$ & $0 \%$ & $57 \%$ & $43 \%$ & $0 \%$ \\
\hline Supervisores & $0 \%$ & $0 \%$ & $50 \%$ & $25 \%$ & $25 \%$ \\
\hline Coordenadores & $0 \%$ & $0 \%$ & $33 \%$ & $33 \%$ & $34 \%$ \\
\hline Outros & $0 \%$ & $0 \%$ & $5 \%$ & $5 \%$ & $90 \%$ \\
\hline Totalizador & $0 \%$ & $0 \%$ & $20 \%$ & $15 \%$ & $65 \%$ \\
\hline
\end{tabular}

Fonte: Elaborado pelos autores a partir de dados da pesquisa, 2009.

Diferentemente de outros casos estudados que apresentaram essa diferença entre setores, nenhum pesquisado apresentou resposta que voltasse a aplicação do BSC para os setores de RH ou de TI, normalmente privilegiados. Não se pode afirmar que isso se deu por falta de envolvimento desses setores, tendo em vista que o coordenador de implantação do BSC era também gerente de TI. Provavelmente, deveu-se ao fato de que nem todos os setores participaram na formatação do mapa estratégico.

Uma questão crítica na implementação do BSC foi o fato de a empresa não ter, na época, sua missão e visão formalmente declaradas, o que evidencia a falta de clareza quanto à perspectiva estratégica do negócio, como advertem Kaplan e Norton (2001). Apesar de inexistentes, $5 \%$ dos pesquisados afirmaram conhecer bem a visão e a missão da empresa. Do total dos respondentes, $14 \%$ dos diretores e gerentes afirmaram conhecer a missão e visão. Embora $86 \%$ dos pesquisados tenha afirmado não conhecê-las bem, nenhum deles assumiu nunca ter ouvido falar deste assunto. 
Tabela 3 - Diferença entre as perspectivas e vinculação dos objetivos

A diferença entre as quatro perspectivas e o motivo de cada objetivo estar relacionado a uma delas era entendido por você e por sua equipe?

\begin{tabular}{|c|c|c|c|c|}
\hline & Totalmente & Razoavelmente & Nunca & $\begin{array}{c}\text { Nunca ouvi falar desse } \\
\text { assunto }\end{array}$ \\
\hline Diretores e Gerentes & $29 \%$ & $57 \%$ & $0 \%$ & $14 \%$ \\
\hline Supervisores & $0 \%$ & $35 \%$ & $0 \%$ & $65 \%$ \\
\hline Coordenadores & $0 \%$ & $17 \%$ & $0 \%$ & $83 \%$ \\
\hline Outros & $0 \%$ & $5 \%$ & $5 \%$ & $90 \%$ \\
\hline Totalizador & $3 \%$ & $15 \%$ & $3 \%$ & $79 \%$ \\
\hline
\end{tabular}

Fonte: Elaborado pelos autores a partir de dados da pesquisa, 2009.

Essa falta de definição da missão e visão adquire relevância ao se tentar avaliar se o mapa estratégico corporativo do BSC traduzia as necessidades da empresa. Embora $71 \%$ dos diretores e gerentes tenham afirmado que o mapa traduzia totalmente as necessidades, e $29 \%$ tenham, afirmado que sim, mas razoavelmente, $68 \%$ do total de todos os outros pesquisados afirmaram nunca ter ouvido falar deste assunto, o que indica o completo desconhecimento das necessidades da empresa.

$\mathrm{O} \mathrm{BSC}$ relaciona os objetivos por meio de causas e efeitos. Os objetivos de uma perspectiva afetam o resultado de objetivos de outras perspectivas. Dos grupos que participaram da definição da estratégia, $86 \%$ dos diretores e gerentes e $38 \%$ dos supervisores creem que as relações de causa e efeito proporcionavam apenas razoavelmente um entendimento desses objetivos. Do total de respondentes, $67 \%$ jamais ouviram falar em relações de causa e efeito, incluindo-se aí os $62 \%$ restantes dos supervisores.

Esse não conhecimento das relações de causa e efeito é confirmado na Tabela 3, em que 57\% dos diretores e gerentes afirmaram que conhece razoavelmente a diferença das quatro perspectivas, enquanto $79 \%$ dos pesquisados confirmaram desconhecer o assunto.

A Tabela 4 evidencia que outro erro fatal da empresa foi em relação à disponibilização da informação. Todo modelo de gestão por indicadores pressupõe o amplo compartilhamento de informações, pois a evolução do processo depende da leitura dos resultados dos indicadores. Para o BSC, isso é vital, pois cada indicador balanceado só pode ser lido e entendido se suas informações e as informações de 
outros indicadores estiverem disponíveis. Na Tabela 4, vê-se que 79\% dos pesquisados não tinham acesso às informações ou não sabia de sua existência, enquanto outros $16 \%$ conseguia acessá-las, porém somente após longa espera. Apenas $29 \%$ dos diretores e gerentes e $13 \%$ dos supervisores tiveram facilidade de acessar, percentual muito baixo considerando-se o total de respondentes e a relevância do acesso às informações para o processo.

Tabela 4 - Disponibilidade das informações

\begin{tabular}{|c|c|c|c|c|}
\hline \multicolumn{5}{|c|}{ Todas as informações de que necessitava estavam disponíveis? } \\
\hline & Sim & $\begin{array}{c}\text { Sim, porém o tempo para } \\
\text { recebê-las era longo }\end{array}$ & Não & $\begin{array}{c}\text { Nunca ouvi falar sobre } \\
\text { esse assunto }\end{array}$ \\
\hline Diretores e Gerentes & $29 \%$ & $43 \%$ & $0 \%$ & $28 \%$ \\
\hline Supervisores & $13 \%$ & $25 \%$ & $0 \%$ & $62 \%$ \\
\hline Coordenadores & $0 \%$ & $33 \%$ & $0 \%$ & $67 \%$ \\
\hline Outros & $0 \%$ & $8 \%$ & $5 \%$ & $87 \%$ \\
\hline Totalizador & $5 \%$ & $16 \%$ & $3 \%$ & $76 \%$ \\
\hline
\end{tabular}

Fonte: Elaborado pelos autores a partir de dados da pesquisa, 2009.

Como relatado, o BSC foi implantado após a contratação de um gestor profissional, o que fez com que toda a equipe passasse por um período de incertezas, pois profissionais estavam sendo trocados enquanto outros conquistavam posição de destaque junto à nova diretoria. A transição gerou, também, conflitos e tensões, que, por sua vez, refletiram em disputas de poder e defesa de território, o que contribui significativamente para o não compartilhamento de informações, dentre outras coisas.

Quando indagados se os indicadores dos objetivos traduziam as reais necessidades de cada objetivo, 68\% dos pesquisados afirmaram não conhecer tais indicadores e $3 \%$ afirmaram que não. Dos $29 \%$ que afirmaram conhecer os indicadores e suas relações com os objetivos, $16 \%$ julgaram que os indicadores traduziam apenas razoavelmente as necessidades dos objetivos, estando incluídos neste percentual $86 \%$ dos gerentes e diretores. Esses dados parecem confirmar a não participação da equipe na implementação do modelo de gestão BSC.

Indagados se os indicadores comuns a mais de um setor eram medidos de forma igual, dos $29 \%$ de pesquisados que conhecem os indicadores, $18 \%$ afirmaram 
que quando aplicados a mais de um setor, eles eram medidos de forma desigual. Quando aplicado de forma errada, o BSC não consegue atingir seu maior objetivo que é o de gerar crescimento na empresa, porém, como o próprio Kaplan afirma, $60 \%$ das empresas que aplicam o BSC não atingem seus objetivos financeiros por problemas de implantação ou execução. Esses resultados confirmam a afirmação feita, anteriormente, sobre a aplicação mais voltada para alguns setores.

Quanto a terem percebido crescimento em seu setor com a utilização do BSC, $77 \%$ dos pesquisados afirmaram que não, enquanto outros $18 \%$ perceberam crescimento razoável e 5\% um grande crescimento. Quanto ao grau em que os gestores conheciam a proposta do BSC e aplicavam seus conceitos no dia a dia, $71 \%$ afirmaram não conhecê-las e outros $26 \%$ as conheciam razoavelmente. Nenhum dos dirigentes ou gerentes, bem como nenhum dos supervisores conhecia totalmente esses conceitos e propostas. Do total dos respondentes, $66 \%$ nunca ouviram falar sobre esse assunto.

Verifica-se que a disseminação do BSC, tarefa de responsabilidade da consultoria contratada, não foi bem executada. Se o modelo não é compreendido, não pode ser bem aplicado. Tendo em vista as respostas a este respeito, infere-se que a consultoria não estava preparada para implantar o BSC em uma empresa do porte da pesquisada. Constata-se, assim, uma terceira grande causa do fracasso. Foi demonstrado anteriormente que a falta de missão e visão e o não envolvimento da equipe geraram uma avalanche de resultados mal sucedidos, porém esse terceiro fator parece ser ainda mais grave, podendo ter contribuído significativamente para a ocorrência dos demais.

Indagou-se, em seguida, se os gestores apoiavam a implantação do BSC, acreditando em sua proposta. Coerentemente com os resultados acerca do questionamento anterior, sobre o conhecimento da proposta, $89 \%$ afirmaram que nenhum ou somente alguns gestores respeitavam e apoiavam o comitê de implantação do BSC. Embora minoritário em relação ao grupo total, esse apoio centrava-se no subgrupo dos diretores e gerentes. 
Perguntados se aceitavam e respeitavam os direcionamentos do comitê do BSC, $76 \%$ dos respondentes afirmaram que não. Dos $24 \%$ que julgaram que sim, a maior concordância está no subgrupo dos diretores e gerentes. Destes, $72 \%$ julgaram que havia aceitação e respeito aos direcionamentos. Quanto ao questionamento se os colaboradores entendiam o que era o BSC, $82 \%$ afirmaram que não. No subgrupo dos diretores e gerentes, nenhum deles afirmou haver plena compreensão. Destes, 57 \% afirmaram haver uma compreensão apenas razoável e 43\% evidenciaram saber que os colaboradores, em geral, não entendiam o que era o BSC. As constatações destas duas questões corroboram os resultados apresentados acerca das primeiras questões do questionário.

Constata-se que a base da implantação não foi bem executada. Não houve preparo suficiente dos gestores, assim como não foram claras as etapas que deveriam ter sido executadas pela consultoria que, dentre outras coisas, não foi capaz de promover as mudanças necessárias para o envolvimento da equipe. Foi argumentado que um dos motivos para o fracasso do BSC teria sido a falta de preparo da consultoria que, embora experiente, não soube lidar com o porte e com as singularidades da empresa. Em processo deste tipo, sabe-se que toda a equipe deve ser desafiada por metas. Porém, $61 \%$ dos respondentes afirmaram não ter conhecimento das metas e $16 \%$ não as julgaram desafiadoras. Ressalta-se que no subgrupo dos diretores e gerentes, nenhum dos respondentes julgou que todas as metas fossem desafiadoras e estimulantes.

A falta de envolvimento não ocorreu apenas na implantação, pois conforme os dados, a gestão continuava centralizadora, mesmo após a mudança do executivo principal. Dos pesquisados, $63 \%$ não tinham nenhum conhecimento acerca de indicadores, $8 \%$ julgaram que os indicadores não traduziam os objetivos, e outros $11 \%$ julgaram que os indicadores eram inatingíveis.

De maneira geral, como os pesquisados não conheciam ou não concordavam com os indicadores, apenas $13 \%$ consideraram fácil medir os indicadores financeiros, e $11 \%$ os não financeiros. No subgrupo dos diretores e gerentes, enquanto 
72\% julgaram os indicadores financeiros de fácil mensuração, 14\% afirmaram que não, e os outros $14 \%$ afirmaram não ter qualquer conhecimento sobre esse assunto.

Quanto à facilidade de mensuração dos indicadores não financeiros, somente $43 \%$ dos diretores e gerentes evidenciaram a dificuldade de mensuração; outros $43 \%$ julgaram que a mensuração não é fácil e os demais $14 \%$ afirmaram desconhecer a questão. Salienta-se que a questão maior não era a facilidade de mensuração, mas sim a própria definição desses indicadores.

A falta de clareza em relação às metas, reflete-se na inexistência de um plano de reconhecimento atrelado ao alcance das metas. De forma unânime, os diretores e gerentes afirmaram que não há nenhum plano nesse sentido, apesar da percepção de cerca de $15 \%$ dos demais respondentes de que havia um plano. Do mesmo modo, a totalidade dos diretores e gerentes afirma não haver um plano de desenvolvimento pessoal ligado ao BSC, visão compartilhada pela grande maioria dos demais respondentes, o que parece evidenciar o desinteresse pelo crescimento dos colaboradores.

Quanto ao tempo de implantação, como visto, a grande maioria dos pesquisados não participou ou não tomou conhecimento do processo. Apenas $8 \%$ dos pesquisados consideraram o tempo destinado para a implantação como suficiente. No subgrupo dos diretores e gerentes, $58 \%$ consideraram o tempo insuficiente e apenas $14 \%$ julgaram o tempo suficiente.

Questionados quanto à capacidade do BSC atender às necessidades da empresa, apenas 3\% dos pesquisados consideraram o BSC como um modelo completo, capaz de atender às necessidades, e $23 \%$ o consideraram adequado para a empresa, desde que feitas adaptações. No subgrupo dos diretores e gerentes, $57 \%$ reconheceram que o BSC precisava de adaptações, enquanto $43 \%$ afirmaram que ele não atendia às necessidades.

Quando perguntados sobre o que ocorreu com as ferramentas utilizadas anteriormente, após a implantação do BSC, 68\% dos entrevistados afirmaram não ter conhecimento desse assunto, embora $71 \%$ dos diretores e gerentes tenham afirmado 
que algumas tenham sido adaptadas e outras abandonadas. O desconhecimento desse fato por grande parte dos colaboradores corrobora o estilo centralizador da gestão, inclusive quanto à disseminação das informações.

Em relação à consultoria responsável pela implantação do BSC, 73\% dos pesquisados sequer chegaram a tomar conhecimento de sua atuação, $3 \%$ julgaram que a consultoria não tinha capacitação técnica e ainda $11 \%$ afirmaram que esta não sabia transmitir seus conhecimentos. Para a totalidade dos diretores e gerentes, a consultoria estava tecnicamente preparada. De uma maneira geral, somente $13 \%$ da totalidade dos respondentes julgavam-na tecnicamente preparada e capaz de transmitir os conhecimentos.

Como evidenciado, dado que a consultoria não conseguiu fazer com que os gestores entendessem os conceitos do BSC, esses gestores não tiveram como atuar como multiplicadores, tampouco puderam envolver suas equipes na execução do planejamento estratégico, que foi desenvolvido apenas por alguns funcionários da empresa. Apenas $2 \%$ dos pesquisados consideraram que a consultoria conseguiu desempenhar bem seu papel durante a implantação do BSC, orientando e esclarecendo os colaboradores para um total entendimento do modelo.

Tabela 5 - Opinião quanto à substituição do BSC

Você concordou com a decisão de substituir o BSC por outro modelo de gestão?

\begin{tabular}{|c|c|c|c|}
\hline & Sim & Não & Nunca ouvi falar sobre esse assunto \\
\hline Diretores e Gerentes & $71 \%$ & $29 \%$ & $0 \%$ \\
\hline Supervisores & $25 \%$ & $13 \%$ & $62 \%$ \\
\hline Coordenadores & $50 \%$ & $0 \%$ & $50 \%$ \\
\hline Outros & $13 \%$ & $8 \%$ & $79 \%$ \\
\hline Totalizador & $25 \%$ & $10 \%$ & $65 \%$ \\
\hline
\end{tabular}

Fonte: Elaborado pelos autores a partir de dados da pesquisa, 2009.

Em função das fragilidades detectadas e da falta de alinhamento com a realidade da empresa, o BSC acabou sendo substituído por outro modelo de gestão, mudança que contou, paradoxalmente, com o apoio de $71 \%$ dos diretores e gerentes, o subgrupo mais diretamente envolvido com a implementação do modelo e que, em grande medida, havia liderado o processo. Da totalidade dos respondentes, apenas 
$10 \%$ afirmaram que o BSC não deveria ter sido substituído, contra $25 \%$ que concordaram com a substituição, e outros $65 \%$ que nem sequer tomaram conhecimento dessa questão. Por fim, uma nova consultoria foi contratada para implantação de um novo modelo de gestão.

\subsection{DISCUSSÃO}

Respondendo ao problema da pesquisa, constata-se que o primeiro fator crítico que impediu a implantação do BSC no Beach Park foi o encastelamento do BSC no topo. Um processo de mudança organizacional, por meio da adoção de um novo modelo de gestão, como observado por Kasurinen (2002), requer o envolvimento de toda a equipe de gestores para a condução e liderança do processo. O fator tempo também foi apontado como inibidor do processo de implantação, como encontrado por Kasurinen (2002) e Chan (2004), o que pode ter prejudicado os líderes no envolvimento de suas equipes, principalmente na atividade de planejamento estratégico, definição de metas e indicadores.

Outra barreira que pode ser destacada é a complexidade do projeto de implantação do BSC, pelo fato do complexo Beach Park se dividir em unidades de negócios diversificadas, o que pode ter provocado a desmotivação para a continuidade do projeto.

Como encontrado em outros estudos (WAGNER; KAUFMANN, 2004; NORTHCOTT; TAULAPAPA, 2012), a dificuldade de se especificar de forma clara a perspectiva estratégica do negócio foi outra barreira à implementação do BSC, o que prejudicou a elaboração do mapa estratégico, a definição das relações de causa e efeito, e dos indicadores, e levou os gestores a compreenderem o BSC como inconsistente.

A falta de um sistema de informação para dar suporte ao projeto BSC foi um dos fatores destacados na empresa analisada como impedimento à sua implementação, prejudicando o processo de comunicação, como encontrado por Chan 
(2004). Outro fator inibidor foi o momento de conflitos e tensões pelo qual a empresa passava no período de implantação do BSC, prejudicando o compartilhamento das informações.

A realização de treinamentos pode contribuir para reduzir a resistência do grupo à implantação do BSC (NORTHCOTT; TAULAPAPA, 2012), podendo a sua inexistência ser considerada mais um fator que contribuiu para inibir sua aplicação.

Acredita-se que um dos principais fatores críticos que trouxeram essas dificuldades foi a inexperiência da consultoria externa contratada para conduzir o processo. Outro fator que pode ser destacado é o histórico de gestão da empresa, que por muito tempo foi conduzida por um estilo de gestão centralizador e autoritário, e somente em 2004 a empresa passou a ter um perfil de gestão mais profissionalizado.

Nessa realidade, a empresa não possuía estratégia, nem visão global já definidas, não havendo um aprendizado anterior dos gestores no processo de gestão de desempenho, o que seria um fator que predisporia melhor a administração da empresa para a implantação do BSC. Ou seja, não há uma cultura de planejamento estratégico, dificuldade que também foi constatado por Marchesan Neto (2002). Ainda, conforme os entrevistados, a gestão continuou centralizadora, mesmo depois da saída do primeiro sócio, o que é prejudicial para a implementação do BSC, que exige uma gestão mais participativa (KASURINEN, 2002).

\section{CONSIDERAÇÕES FINAIS}

O Balanced Scorecard é um modelo de gestão difundido mundialmente, usado pelas organizações para orientar o processo de implantação da estratégia baseado em cinco princípios gerenciais: tradução da estratégia em termos operacionais; alinhamento de toda a organização à estratégia; implementar a estratégia passa a ser responsabilidade de todos os funcionários; a estratégia passa a ser um processo contínuo; mobilização da mudança a partir da liderança executiva. As pesquisas demonstram, no entanto, que o modelo é de difícil aplicação, pois se trata 
ele mesmo de um processo de mudança organizacional, cujo ponto crítico é a transformação da cultura organizacional.

Estudos anteriores sobre a implantação do BSC no campo da indústria do entretenimento apontam dificuldades relacionadas ao esforço da liderança no envolvimento das equipes no desenvolvimento do modelo BSC, e em conscientizá-los quanto à sua importância. A ausência da cultura do planejamento estratégico é o fator complicador desse processo, gerando resistência e desinteresse das partes envolvidas pelo projeto de mudança, definição equivocada da própria estratégia de negócio, não atendimento à totalidade das perspectivas do BSC, e dificuldades em se determinar e mensurar o desempenho que se deseja alcançar.

Atendendo ao primeiro objetivo da pesquisa, os resultados revelaram que os principais fatores impeditivos para a formulação da estratégia da empresa foi a ausência da cultura do planejamento estratégico e do envolvimento planejado de todos os níveis do corpo funcional na implantação do Balanced Scorecard, que ficou restrita à participação dos diretores e gerentes, e de alguns supervisores. O BSC deve ser alinhado de cima para baixo, permitindo que todos dentro da organização conheçam e entendam a estratégia.

Com relação ao segundo objetivo da pesquisa, a falta de clareza quanto à perspectiva estratégica do negócio, pela inexistência de uma missão e visão formalmente declaradas no momento da implantação do BSC, foi um dos fatores impeditivos na implantação do mapa estratégico. Essa falta de cultura de planejamento, na identificação e discussão sistêmica dos processos críticos, desde o período anterior à implantação do BSC, fez com que os objetivos definidos na constituição do mapa fossem destoantes dos reais problemas da organização. Como segundo fator impeditivo, constatou-se que boa parte dos gestores pesquisados nunca ouviu falar sobre o mapa estratégico, o que pode ser explicado pela não realização de treinamento sobre o tema.

O terceiro objetivo do estudo foi destacar os fatores impeditivos do uso de indicadores balanceados para a leitura de resultados. A ausência de um amplo 
compartilhamento de informações foi um dos fatores impeditivos encontrados. Dentre os gestores pesquisados, a maior parte revelou que não possuía acesso às informações ou desconhecia sua existência. Ao mesmo tempo, houve pouco tempo para a elaboração adequada desses indicadores, e boa parte dos pesquisadores considerou os indicadores destoantes da realidade da organização.

Quanto ao quarto objetivo desta pesquisa, considera-se que a falha da consultoria na condução do processo, a postura centralizadora da gestão e a ausência da cultura do planejamento estratégico foram os principais fatores impeditivos para a conclusão da implantação do BSC.

Na promoção da mudança organizacional, o envolvimento adequado das lideranças e o apoio da gestão da cúpula para a disseminação e execução são essenciais. Também o histórico de uma gestão voltada para o aprendizado, serve como base para a definição adequada das necessidades críticas da organização, e na definição dos indicadores adequados, o que se torna complexo em uma empresa sem cultura de planejamento.

Em síntese, e respondendo o problema desta pesquisa, quanto aos fatores críticos ou de risco identificados na literatura como prejudiciais à implantação do BSC na empresa, foram constatados na organização todos os fatores relacionados ao envolvimento da equipe, à estrutura da organização e à implantação. Na dimensão "Processos e objetivos", constatou-se problemas na circulação das informações e diferenças na definição das medidas. Quanto à dimensão "Influências externas", podese considerar que a consultoria não apresentou a experiência necessária para lidar com o porte e campo de atuação da organização.

O estudo apresenta limitações relacionadas ao escopo da pesquisa, por contemplar somente uma organização; e ao método de coleta de dados, em que poderia ter sido feito uso da pesquisa documental.

Para pesquisas futuras, sugere-se a realização de estudos empíricos cujo objetivo seja a constituição de um modelo de implementação do BSC em organizações da indústria de entretenimento, tendo em vista que a própria ausência de um modelo 
disponível pode ser considerada um dos obstáculos para a aplicação do BSC nas empresas desse campo. Usar as quatro perspectivas do BSC para compreender a gestão estratégica do desempenho dessas organizações também pode ser um caminho alternativo interessante, como feito na pesquisa da rede hoteleira destacada neste estudo.

\section{CRITICAL FACTORS IN IMPLEMENTING THE BALANCED SCORECARD-BSC}

\section{ABSTRACT}

Several issues can be raised regarding the critical factors for implementing management models such as the Balanced Scorecard (BSC). The success demands the understanding of the model by the implementation team and the workers involved. The entertainment industry, to which the Beach Park Hotel and Tourism, presents peculiarities that make the implementation of a management model a bigger challenge, and a segment that tends to grow at a rate of 10, 6\% per year until 2016. Focusing the organization and context, this study aims to identify the critical factors of implementation of the BSC, through a case study, descriptive. The results showed the following critical factors for the implementation of the BSC: the absence of a culture of strategic planning, the complexity of the business and project, the history of a management style centralized and authoritarian, the centralization of the BSC at the top, restriction of management time to devote to the project; the absence of an information system, to support the project; not performing training and the lack of external consultants. In promoting organizational change, lacked adequate involvement of the leadership and and the support of the management of the dome. In successful cases, the history of management-oriented learning serves as the basis for a proper definition of the critical needs of the organization, and defining the appropriate indicators, factors that, in the case in focus, proved absent in a company without culture of planning.

Keyword: Critical Factors. Balanced Scorecard. Entertainment Industry. 


\section{REFERÊNCIAS}

ANDRADE, Marcos; HOFFMAN, Valmir. Planejamento estratégico e o Balanced Scorecard: estudo de caso. In: ENCONTRO NACIONAL DE ENGENHARIA DE PRODUÇÃO, 24, 2004, Florianópolis. Anais... Florianópolis: ABEPRO, 2004.

ATTADIA, L. C. do L.; CANEVAROLO, M. E. \& MARTINS, R. A. Balanced Scorecard: uma análise crítica. In: ENCONTRO NACIONAL DE ENGENHARIA DE PRODUÇÃO, 23, 2003, Ouro Preto, Anais... Ouro Preto: UFOP, 2003. 1 CD-ROM.

BARDIN, L. Análise de conteúdo. Lisboa: Edições 70, 2003.

BEACH PARK HOTÉIS E TURISMO S/A. Estrutura do Complexo. Disponível em: < http://www.beachpark.com.br/site/pt/complexo/complexo-estrutura.asp >. Acesso em: 9 jul. 2012.

BEBER, Sidinei; RIBEIRO, José; KLIEMANN NETO, Francisco. Análise das causas do fracasso em implantações do BSC. Revista Produção Online, v.6, n.2, ago.2006. Disponível em: <http://producaoonline.org.br/index.php/rpo/article/viewFile/284/360>. Acesso em: 25 jul. 2011.

BECHARA, Marco. Modelo M4 para gestão de legados de megaeventos esportivos com foco na responsabilidade social e políticas públicas. In: RODRIGUES, Rejane Penna; MAGALHÃES PINTO, Leila Mirtes; TERRA, Rodrigo; DACOSTA, Lamartine P. Legados para megaeventos esportivos. Brasília: Ministério do Esporte, 2008.

CELESTINO, Maxwell dos Santos. Utilização de indicadores financeiros e nãofinanceiros na gestão de hotéis no Rio Grande do Norte: um estudo sob a ótica do Balanced Scorecard. 2003. 180p. Dissertação (Mestrado em Ciências Contábeis) Programa Multiinstitucional e Inter-regional em Ciências Contábeis, Universidade de Brasília, Universidade Federal da Paraíba, Universidade Federal de Pernambuco, Universidade Federal do Rio Grande do Norte, 2003.

CHAN, Yee-Ching Lilian. Performance measurement and adoption of balanced scorecards: A survey of municipal governments in the USA and Canadá. International Journal of Public Sector Management, v.17, n.3, p. 204 - 221, 2004.

CROCE FILHO, Jair; COSTA, Helder Gomes. As principais falhas apresentadas na literatura em relação à implantação do BSC nas organizações. In: SIMPÓSIO DE EXCELÊNCIA EM GESTÃO E TECNOLOGIA, 7, 2010, Rio de Janeiro. Anais... Rio de Janeiro: AEDB, 2010. 
CRUZ JUNIOR, Augusto de Toledo; CARVALHO, Marly Monteiro de; LAURINDO, Fernando José Barbin. Estratégia e Estrutura: em busca do alinhamento organizacional em um clube social esportivo. Gestão e Produção, v.12, n.3, p.429-441, set.-dez. 2005.

FOREMAN, Julie A. Corporate governance in the australian football league: a critical evaluation. 358f. 2006.Tese (Doutorado em Filosofia). University of New South Wales Sydney, Canberra, Austrália, 2006.

JEACLE, Ingrid. "Going to the movies": accounting and twentieth century cinema. Accounting, Auditing \& Accountability Journal, v. 22, n. 5, p. 677-708, 2009.

LUNKES, Rogério João. Manual de Contabilidade Hoteleira. São Paulo: Atlas, 2004.

KAPLAN, Robert S., NORTON, David P. The Balanced Scorecard: Measures that drive performance. Harvard Business Review, v.70, n.1, p. 71-79, jan-fev 1992.

Organização orientada para a estratégia: como empresas que adotam o Balanced Scorecard prosperam no novo ambiente de negócios. Rio de janeiro: Campus, 2001.

KASURINEN, Tommi. Exploring management accounting change: the case of balanced scorecard implementation. Management Accounting Research, v.13, n.3, p.323-343, 2002.

LAMPEL, Joseph; LANT, Theresa; SHAMSIE, Jamal. Equilíbrio em cena: o que aprender com as práticas organizacionais das indústrias culturais. Revista de Administração de Empresas: RAE, v.49, n.1, p.19-26, jan.-mar. 2009.

MOREIRA, Herivelto; CALEFFE, Luiz Gonzaga. Metodologia de pesquisa para o professor pesquisador. Rio de Janeiro: DP\&A, 2006.

MARCHESAN NETO, Armando. Sistemas de avaliação de desempenho: implantação do Balanced Scorecard em uma empresa de serviços. 2002. 175f. Dissertação (Mestrado em Engenharia de Produção). Universidade Metodista de Piracicaba, Santa Bárbara d'Oeste, 2002.

NORTHCOTT, Deryl; TAULAPAPA, Tuivaiti Ma'amora.Using the balanced scorecard to manage performance in public sector organizations: issues and challenges.

International Journal of Public Sector Management, v. 25, n. 3, p. 166- 191, 2012.

PRIETO, Vanderli; PEREIRA, Fábio; CARVALHO, Marly; LAURINDO, Fernando. Fatores críticos na implementação do Balanced Scorecard. Gestão \& Produção, São Paulo, v. 13, n. 1, p. 81-92, Jan.-Abr. 2006. 
PROPMARK. Brasil se tornará o 70 maior mercado de mídia e entretenimento em 2016. Disponível em: <http://www.midiabsb.org.br/?p=1843>. Acesso em: 13 jul. 2012.

ROCHA, Irani; LAVARDA, Carlos Eduardo Facin. Retrospectiva bibliográfica sobre o balanced scorecard (BSC) como instrumento de planejamento e controle nas empresas. Revista de Contabilidade do Mestrado em Ciências Contábeis da UERJ, Rio de Janeiro, v. 16, n. 1, p. 28 - p. 34, jan./abril, 2011.

ROSA, Fabricia Silva da; LUNKES, Rogério João. Diagnóstico sobre a Avaliação de Desempenho em Empresas Hoteleiras: Uma Contribuição ao Estudo sobre a Elaboração de Balanced Scorecard. In: SIMPÓSIO DE EXCELÊNCIA EM GESTÃO E TECNOLOGIA, 3, 2006, Rio de Janeiro. Anais... Rio de Janeiro: AEDB, 2006.

SANTOS, Eduardo Manuel Torres dos. Balanced Scorecard para o sector da cultura: aplicação prática num teatro nacional. 2011. 47f. Dissertação (Mestrado em Contabilidade, Fiscalidade e Finanças empresariais). Universidade Técnica de Lisboa, Lisboa, 2011.

UNCTAD. The Creative Economy Report: 2010. Disponível em: < http://www.unctad.org/en/docs/ditctab20103_en.pdf>. Acesso em: 20 nov.2011.

TRIGO, Luiz Gonzaga Godoi. Entretenimento: uma crítica aberta. São Paulo: Editora Senac, 2003.

VITAL, Soraya. Aplicação do Balanced Scorecard no planejamento do departamento de administração da UFSC. Dissertação (Mestrado em Administração de Empresas). Florianópolis: Universidade Federal de Santa Catarina, 2006.

YEUNG, Allen Kwokwah; CONNELL, Julia. The Application of Niven's Balanced Scorecard in a Not-For-Profit Organization in Hong Kong: What Are the Factors for Success?, Journal of Asia Business Studies, v. 1, n.1, p. 26- 33, 2006.

YIN, Robert K. Estudo de caso. 3. ed, Porto Alegre: Bookman, 2005.

YOUNG, S. Mark; STEDE, Wim A. Van der; GONG, James J. Organization control and management accounting in context: a case study of the US motion picture industry. In: BHIMANI, Alnoor (org.). Contemporary Issues in Management Accounting. New York: Oxford University Press, 2006. 
WAGNER, Stephan M.; KAUFMANN, Lutz. Overcoming the main barriers in initiating and using purchasing-BSCs. Journal of Purchasing \& Supply Management, v. 10, n.6, p.269-281, 2004. 